\title{
ЛИЧНОСТНЫЕ ОСОБЕННОСТИ ЖЕНЩИН С РЕПРОДУКТИВНОЙ ДИСФУНКЦИЕЙ
}

\section{PERSONAL CHARACTERISTICS OF WOMEN WITH REPRODUCTIVE DYSFUNCTION}

\section{A. Eremishkina \\ G. Shurukhina \\ A. Valishina}

Summary: The aim of the study was to study the personal characteristics of women with reproductive dysfunction. Identified personality traits in women with reproductive dysfunction.

Women with reproductive dysfunction who have children are characterized by the formation of fundamental trust in the world, adequate self-esteem, involvement in personal and social life, are risky, and are able to find ways out of non-standard situations.

Women with reproductive dysfunction, who do not have children, feel threatened by the world around them, devalue themselves, feel fear and do not dare to take risks in non-standard situations, at the slightest setbacks they are disappointed in themselves and their actions, more often choose ineffective coping strategies, being in a depressed state. Based on the results of empirical research, psychological correction programs have been developed aimed at developing positive thinking, changing the emotional sphere, developing self-regulation skills, reducing psychological adaptation after perinatal losses in women with primary and secondary infertility. The programs are recommended for use in the professional activities of practical and perinatal psychologists.

Keywords: emotional processes, cognitive approaches, reproductive dysfunction, psychological infertility.
Еремишкина Алла Раилевна

ФГБОУ ВО «Башкирский государственный педагогический университет им. М. Акмуллы», г. Уфа alika23@mail.ru

Шурухина Галина Анатольевна

К.nсх.н., дочент, ФГБОУ ВО «Башкирский государственный педагогический университет им. М. Акмуллы», г. Уфа 230659@mail.ru

Валишина Альбина Маратовна старший преподаватель, ФГБОУВО «Башкирский государственный педагогический университет им. М. Акмуллы», г. Уфа aam80@mail.ru

Аннотация: Целью исследования явилось изучение личностных характеристик женщин с репродуктивной дисфункцией. Выявлены личностные особенности у женщин с репродуктивной дисфункцией.

Женщины с репродуктивной дисфункцией, имеющие детей характеризуются сформированностью фундаментального доверия к миру, адекватной самооценкой, вовлеченностью в личную и общественную жизнь, рискованны, умеют находить выходы из нестандартных ситуаций.

Женщины с репродуктивной дисфункцией, не имеющих детей, испытывают угрозу от окружающего мира, обесценивают себя, испытывают страх и не решаются рисковать в нестандартных ситуациях, при малейших неудачах разочаровываются в себе и своих действиях, чаще выбирают неэффективные копинг-стратегии, находясь в депрессивном состоянии.

По результатам эмпирического исследования разработаны программы психологической коррекции, направленные на развитие позитивного мышлении, изменение эмоциональной сферы развитие навыков саморегуляции, сокращения психологической адаптации после перинатальных потерь у женщин с первичным и вторичным бесплодием. Программы рекомендованы к использованию в профессиональной деятельности практических и перинатальных психологов.

Ключевые слова: эмоциональные процессы, когнитивные подходы, нарушение репродуктивной функции, психологическое бесплодие.

ясного генеза.

По данным Всемирной Организации Здравоохранения (ВО3), в мире около 80 миллионов пар являются бесплодными. В России свыше 15\% пар имеют тот же диагноз, что по критериям ВОЗ считается угрозой национальной безопасности страны [3].

Эмоции - «психическое отражение в форме непосредственного пристрастного переживания жизненного смысла явлений и ситуаций, обусловленного отношением их объективных свойств к потребностям субъекта» [3, C.461]. 
С точки зрения воздействия на жизнедеятельность человека, эмоции делятся на стенические, стимулирующие деятельность, увеличивающие энергию побуждающие к поступкам, и астенические, характеризующиеся пассивностью и скованностью. Эмоции по-разному влияют на поведение человека, это зависит от ситуации и индивидуальных особенностей. М. Арнольд рассматривала эмоциональный процесс, как когнитивную теорию эмоций одной из первых. В когнитивном подходе эмоциональный процесс - это последовательность, возникающая с восприятия стимула, за которым следует оценочное суждение, которое, в свою очередь, запускает эмоциональную реакцию [10]. 3. Фрейд в психоаналитической теории, рассматривал только негативные эмоции, понимание аффекта основывал на концепции влечений и, по сути, идентифицировал и аффект, и влечение с мотивацией [7].

Отечественные психологи С.М. Емельянов (2004); Е.С. Миронова (2011); Ю.Г. Себелева (2014) отмечают, что «многое из того, что в учении об эмоциях по традиции называют словом «теория», по существу представляют собой скорее отдельные фрагменты, лишь в совокупность приближающиеся к идеально исчерпывающей теории», свое понимание эмоций понимают, как биологический продукт эволюции.

Эмоции имеют тесное взаимодействие с психологическим состоянием человека, значимо влияют на его действия, а также образ мыслей и физиологическое здоровье.

Экспансивная жизнедеятельность женщин находится в зависимости от восприятия, запаса знаний и социального опыта. С другой стороны, изменения в эмоциональном плане, жизни женщин отображают изменения в когнитивном и социальном развитии, и этот эмоциональный опыт увеличивает прогресс в этой области.

Начиная с 90-х готов, отечественные психологи интенсивно изучают психотерапевтические, а также психосоматические симптомы патологии репродуктивной функции здоровья человека, в том числе перинатального периода.

Однако, Т.Ю. Юдеева и Н.В. Скобинева указывают на то, что женщины с нарушениями и без нарушений репродуктивной сферы не различаются по устойчивым личностным качествам, не относящиеся к адаптационным механизмам [9]. К таким механизмам принадлежат: специфика когнитивного поведения, интроверсия, экстраверсия, а также такие социальные параметры, как: возраст, образование, количество детей, жилищные и материальные условия.

Наличие двух составляющих: половой и родительской - отображает психологическое содержание репро- дуктивной сферы, которые обладают схожими физиологическими свойствами, тем не менее, эти составляющие имеют значимо несхожие психические компоненты. Физиология и психика человека находятся в тесной взаимосвязи, а для здоровой реализации репродуктивной сферы важно их согласованное функционирование. Искаженная сформированность психического компонента выражается в форме психологической неготовности к осуществлению репродуктивной функции.

М.Г. Рябова считает, что психологическое бесплодие - это защитная функция от какого-либо негативного фактора [4]. В этом случае выделяют три группы женщин с нарушением репродуктивной функции: психологическое бесплодие, которое может исчезнуть после обследования у репродуктолога, когда женщина убеждается в том, что ее здоровье в норме, и она способна иметь детей; бесплодие, вызванное социально-экономическими факторами, и бесплодие, в результате глубоких психологических травм детства.

В рамках психосоматических аспектов бесплодия Е.В. Белинская отмечает, что женщины с проблемой функционального бесплодия не осознают у себя тревожность и непринятие в отношении деторождения, у женщин с репродуктивной дисфункцией выявляется отрицательная установка к материнству, то есть находится в зависимости от идентификации «Я-женщина» [1].

Н.А. Богдан отмечает, что у женщин, психологическая фертильность которых нарушена или искажена, выявляется внутренний конфликт в психологическом принятии своего пола, которая нередко проявляется, как следствие дисфункциональных взаимоотношений с родителями в детстве [2].

Бесплодие сопровождает множество психологических факторов: это страхи материнства, беременности, родов; деструктивные схемы и установки, отрицательный опыт, конфликтность с близкими; эмоциональная неустойчивость и инфантилизм; неготовность к материнству, изменению образа жизни. Все эти факторы: аффективные, когнитивные, поведенческие, личностные, мотивационные негативным образом влияют на репродуктивную функцию и чем их больше, соответственно, тем выше риск обрести фертильность деторождения.

Личностный профиль бесплодных женщин включает в себя заниженную самооценку и неудовлетворенность собой, противоречие между самооценкой и своими идеалами [6].

Г.Г. Филиппова указывает на то, что регулярные попытки оплодотворения и зачатия порождают стойкое чувство тревожности и депрессии у женщины и формируют ощущение социальной неполноценности, выступая мощным стрессом и формируя долговременную 
фрустрацию, приводящую к депрессивному состоянию. Это подтверждает, что у женщин с бесплодием наблюдаются нарушения психоэмоциональной сферы [5].

Цель исследования: изучение личностных особенностей женщин с репродуктивной дисфункцией. Методы эмпирического исследования -тестирование с использованием методик: «Тест экзистенциальных мотиваций» (ТЭМ) А. Лэнгле, П. Эдхарда, «Тест жизнестойкости» С. Мадди (адаптация Д.А. Леонтьева), с использованием метода матемтической статистики U-критерий МаннаУитни. Результаты данного исследования приведены ниже (таблица 1).

В исследовании приняли участие 80 женщин, состоящих в браке в возрасте от 29 до 39лет. В 1 группу вошли 40 женщин с репродуктивной дисфункцией, родившие детей, во 2 группу вошли 40 женщин с репродуктивной дисфункцией, не имеющих детей. Тестирование проходило онлайн, при помощи Google-форм.

Таблица 1.

Результаты сравнительного анализа экзистенциальных мотиваций участниц исследования («Тест экзистенциальных мотиваций» (ТЭМ) А. Лэнгле, П. Эдхарда)

\begin{tabular}{|l|c|c|c|c|}
\multirow{2}{*}{\multicolumn{1}{|c|}{ Шкалы методик }} & \multicolumn{2}{|c|}{ Средние значения } & \multirow{2}{*}{ Өэмп. } & $\mathrm{p}_{\text {эмп. }}=$ \\
\cline { 2 - 5 } & 1 группа & 2 группа & & $\mathbf{0 , 0 0 0}$ \\
\hline Фундаментальное доверие & 24 & 17,8 & 415,0 & $\mathbf{0}$ \\
\hline $\begin{array}{l}\text { Фундаментальная ценность } \\
\text { жизни }\end{array}$ & 25,3 & 23,5 & 687,5 & 0,228 \\
\hline Самоценность & 26,8 & 19 & 369,0 & $\mathbf{0 , 0 0 2}$ \\
\hline Смысл жизни & 23,3 & 22 & 736,5 & 0,605 \\
\hline
\end{tabular}

Примечание: 1 группа - женщины с репродуктивной дисфункцией, родившие детей; 2 группа - женщины с репродуктивной дисфункцией без детей

* - различия достоверны при $\mathrm{p}_{\text {эмп. }}<0,05$.

Согласно полученным значениям женщины с репродуктивной дисфункцией, не имеющие детей, в меньшей мере испытывают доверие к миру ( $\left.p_{\text {эмп. }}=0,000\right)$, а их ощущение самоценности значимо ниже $\left(p_{\text {эмп. }}=0,002\right)$ как и общий показатель экзистенциональных мотиваций $\left(\mathrm{p}_{\text {эмп. }}=0,000\right)$. Исходя из полученных значений, можно утверждать, что для этих женщин являются характерными негативное восприятие окружающего мира, ожидание угрозы своим планам со стороны окружающих их людей и обстоятельств. Мир воспринимается как враждебный и опасный. Эмоциональное состояние характеризуется хроническим напряжением, стрессом, вызывающим и различные соматические расстройства. При этом они склонны значительно занижать ценности своей личности, воспринимать других как более значимых и успешных. Все это и обуславливает крайне низкие значения общей выраженности экзистенциальных мотиваций женщин с репродуктивной дисфункцией, не имеющих детей.

Результаты статистического исследования «Тест жизнестойкости» С. Мадди (адаптация Д.А. Леонтьева), приведены ниже (таблица 2).

Таблица 2.

Средние значения переменных жизнестойкости у женщин, имеющих детей, и женщин, с репродуктивной дисфункцией («Тест жизнестойкости» С. Мадди (адаптация Д.А. Леонтьева))

\begin{tabular}{|l|c|c|c|c|}
\multirow{2}{*}{\multicolumn{1}{|c|}{ Шкалы методик }} & \multicolumn{2}{|c|}{ Средние значения } & \multirow{2}{*}{ Uэмп. } & \multirow{2}{*}{ рэмп. $=$} \\
\cline { 2 - 4 } & 1 группа & 2 группа & & \\
\hline Вовлеченность & 29,1 & 15,3 & 319,0 & $\mathbf{0 , 0 0 0}$ \\
\hline Контроль & 19 & 19,6 & 789,5 & 0,927 \\
\hline Принятие риска & 14 & 6,9 & 330,0 & $\mathbf{0 , 0 0 0}$ \\
\hline Жизнестойкость & 62,7 & 41,2 & 281,0 & $\mathbf{0 , 0 0 0}$ \\
\hline
\end{tabular}

Примечание: 1 группа - женщины с репродуктивной дисфункцией, родившие детей; 2 группа - женщины с репродуктивной дисфункцией без детей

* - различия достоверны при $\mathrm{p}_{\text {эмп. }}<0,05$

Проведенный статистический анализ выявил значимые различия по шкале «Вовлеченность». Женщины, не имеющие детей с репродуктивной дисфункцией второй группы ( $\left.p_{\text {эмп. }}=0,000\right)$, чаще проявляют выраженную неготовность к риску, отказываются от вовлеченности в происходящее события. Полученные значения позволяют констатировать, что для женщин с репродуктивной дисфункцией, не имеющих детей, характерен страх перед событиями, связанными с риском, они боятся любых кризисов, всего того, что может вызвать у них чувство утраты чего-то значимого. Данные переживания делают невозможным освоение нового, препятствуют развитию личности в целом. Также они стараются не вовлекаться в события окружающего мира, что на наш взгляд свидетельствует о психологической травме, попытке отрешиться от всего, что с ними происходит, в том числе и от положительных моментов в своей жизни, исключая возможность формирования нового положительного опыта. Для таких женщин (вторая группа) характерна низкая жизнестойкость, а для преодоления своих трудностей необходима помощь окружающих их людей.

Статистически значимые различия получены по шкале «Принятие риска» $\left(p_{\text {эмп. }}=0,000\right)$. Женщины репродуктивной функцией, имеющие детей (первая группа), склонны воспринимать события, происходящие с ними гораздо более позитивно, чем женщины с репродуктивной дисфункцией, не имеющими детей (вторая группа). Женщины, входящие в первую группу, убеждены, что все, что с ними происходит, ведет к саморазвитию, обогащает опыт, и, в конечном счете, делает более мудрыми. 
Они готовы рисковать, и понимают, что жизнь без трудностей невозможна.

Во 2 же группе ярко у женщин с репродуктивной функцией выражено стремление избежать риска. Возможно, это связано с угнетенным психологическим состоянием женщин с первичным бесплодием, психологической травмой, вызванной их непростым положением, потеря ценности материнства ведет к крайне негативным переживаниям.

Статистически значимые различия получены по шкале «Жизнестойкость» ( $\left.p_{\text {эмп. }}=0,000\right)$. Женщины с репродуктивной функцией, имеющие детей (первая группа), значительно более жизнестойки, чем женщины с репродуктивной дисфункцией, не имеющие детей (вторая группа). Иными словами, представители первой группы более стойко справляются с проблемами и неприятностями в своей жизни, идут к цели, преодолевая препятствия.

По шкале «Контроль» показатели двух групп респондентов не имеют статистически значимых различий и находятся в пределах средних значений. Полученные результаты указывают на то, что, женщины с репродуктивной дисфункцией обеих групп склонны к контролю своего поведения, планированию, верят в собственные силы, могут влиять на негативные факторы, но у женщин, входящих во вторую группу, большая выраженность перечисленных характеристик.

\section{Выво $\Delta ы$}

Таким образом: у женщин с репродуктивной дисфункцией, имеющих детей сформировано фундаментальное доверие к миру, развита самоценность, ярче проявляется вовлеченность в личную и общественную жизнь. Они позволяют себе рисковать, если риск нужен для достижения важной для них цели, умеют противостоять стрессам и находить выходы из нестандартных ситуаций.

Женщины с репродуктивной дисфункцией, не имеющих детей, часто испытывают угрозу от окружающего мира, как правило, обесценивают себя во всех жизнедеятельности, испытывают негативные эмоции перед всем новым, отказываются от риска, так как из-за низкой жизнестойкости боятся ошибиться и разочароваться, прежде всего в самом себе и своих действиях, больше дезориентированы, не уверены в себе, и чаще выбирают неэффективные копинг-стратегии, находясь в депрессивном состоянии.

По результатам эмпирического исследования разработаны программы психологической коррекции, направленные на развитие позитивного мышлении, изменение эмоциональной сферы развитие навыков саморегуляции, сокращения психологической адаптации после перинатальных потерь у женщин с первичным и вторичным бесплодием. Программы рекомендованы к использованию в профессиональной деятельности практических и перинатальных психологов.

\section{ЛИТЕРАТУРА}

1. Белинская Е.В. Психологические особенности женщин, страдающих бесплодием [Текст] / Е.В. Белинская // Педагогика и психология: актуальные вопросы теории и практики: материалы междунар. Науч.-практ. Конф. - Чебоксары: ЦНС «Интерактив плюс», 2013. - С. 148-151.

2. Богдан Н.А. Психологические проблемы, сопровождающие проблему бесплодия и возможности оказания психологической помощи в процессе его лечения методом ЭКО [Текст] / Н.А. Богдан // Перинатальная психология и медицина, психосоматические расстройства в акушерстве, гинекологии, педиатрии и терапии: матер. Всерос. конф. - Иваново, 2001. - С. 98-101.

3. Руководство В0З по стандартизованному обследованию и диагностике бесплодных супружеских пар [Текст] / пер. с англ. Р.А. Нерсеяна. - 4-е издание. М.: Изд-во «МедПресс», 1997. -91 с.

4. Рябова М.Г. Индивидуально-психологические особенности женщин с различными типами нарушения репродуктивной функции [Текст] / М.Г. Рябова // Вестник ТГУ. - 2013. - №9 (125) - С. 190-198.

5. Филиппова Г.Г. Нарушения репродуктивной функции и их связь с нарушениями в формировании материнской сферы [Текст] / Г.Г. Филиппова // Журнал практического психолога. - 2003. - №4-5. - С. 82-108.

6. Фоменко Г.Ю. Психологические проблемы женского бесплодия в контексте личностных противоречий (экзистенциальные аспекты) [Текст] / Г.Ю. Фоменко // Человек. Сообщество. Управление. - 2008. - № 4. - С. 17-29.

7. Фрейд 3. Введение в психоанализ. Лекции [Текст] / 3. Фрейд. - М.: Эксмо, 2018. - 480 с.

8. Шумский В.Б. Тест экзистенциальных мотиваций в межличностных отношениях: разработка и апробация [Текст] / В.Б. Шумский, Е.М. Уколова // Экзистенциальный анализ. - 2012. - № 4. - С. 187-202.

9. Юдеева Т.Ю. Исследование психологических факторов женского бесплодия [Текст] / Т.Ю. Юдеева, Н.В. Скобинева // Сб. материалов науч. конф. «Психиатрия на этапах реформ: проблемы и перспективы» (Казань, 23-26 сентября 2015 г.) / Министерство здравоохранения Российской Федерации, Министерство здравоохранения Республики Татарстан, и др. - СПб.: 000 «Альта Астра», 2015. - С. 347-348.

10. Arnold M. B. Emotion, motivation and-the limbic system [Text] / M. B. Arnold // Annual N. Y. Acad. Science 1969. - V. 159. - № 3.

(c) Еремишкина Алла Раилевна (alika23@mail.ru), Шурухина Галина Анатольевна (230659@mail.ru), Валишина Альбина Маратовна (аат80@таil.ru). 